\title{
Hormone Replacement Therapy After Gynaecological Malignancies: a Review Article
}

\section{Hormonersatztherapie nach gynäkologischen Malignomen: eine Übersichtsarbeit}

(c) (1) (오) $\ominus$

\author{
Authors \\ Marina Sourouni, Ludwig Kiesel \\ Affiliation \\ Klinik für Frauenheilkunde und Geburtshilfe, \\ Universitätsklinikum Münster, Münster, Germany
}

Key words

hormone replacement therapy (HRT), ovarian cancer, BRCA mutation, breast cancer, endometrial cancer, cervical cance

Schlüsselwörter

Hormonersatztherapie (HRT), Ovarialkarzinom, BRCA-Mutation, Mammakarzinom, Endometriumkarzinom, Zervixkarzinom

received

6.1. 2021

accepted after revision

12.2. 2021

Bibliography

Geburtsh Frauenheilk 2021; 81: 549-554

DOI 10.1055/a-1390-4353

ISSN 0016-5751

(c) 2021. The Author(s).

This is an open access article published by Thieme under the terms of the Creative Commons Attribution-NonDerivative-NonCommercial-License, permitting copying and reproduction so long as the original work is given appropriate credit. Contents may not be used for commercial purposes, or adapted, remixed, transformed or built upon. (https://creativecommons.org/licenses/by-nc-nd/4.0/)

Georg Thieme Verlag KG, Rüdigerstraße 14,

70469 Stuttgart, Germany

Correspondence

Dr. med. Marina Sourouni

Klinik für Frauenheilkunde und Geburtshilfe,

Universitätsklinikum Münster

Albert-Schweitzer-Straße 33, 48149 Münster, Germany

Marina.Sourouni@ukmuenster.de

Deutsche Version unter:

https://doi.org/10.1055/a-1390-4353

\begin{abstract}
Rapid advances in oncology have led to an increased survival rate in cancer patients, who live long enough to reach the natural age of menopause or experience the end of gonadal function as a side effect of oncological treatment. Survivors after gynaecological malignancies are a major challenge as these diseases are hormone-dependent and hormone replacement therapy (HRT) possibly increases the risk of recurrence. This article is based on a selective literature search for relevant studies and guidelines regarding HRT after gynaecological malignancies and provides a broad overview of current research. The data for assessing the oncological safety of HRT after gynaecological malignancy are insufficient overall. According to current knowledge, HRT is fundamentally contraindicated after breast and endometrial cancer. After ovarian cancer, HRT can be used after assessment of the risks and benefits, while there is usually no contraindication to HRT after vulvar, vaginal or cervical cancer.
\end{abstract}

\section{ZUSAMMENFASSUNG}

Der rasche Fortschritt in der Onkologie führt zu einer erhöhten Überlebensrate onkologischer Patienten, die lange genug leben, um das natürliche Alter der Menopause zu erreichen, oder als Nebeneffekt der onkologischen Therapie die Beendigung der Gonadenfunktion erleben. Überlebende nach gynäkologischen Malignomen sind die große Herausforderung, da diese Erkrankungen hormonabhängig sind und eine Hormonersatztherapie (HRT) möglicherweise das Rezidivrisiko steigert. Diese Arbeit basiert auf einer selektiven Literaturrecherche nach relevanten Studien und Leitlinien über die HRT nach gynäkologischen Malignomen und bietet einen breiten Überblick über den aktuellen Forschungsstand. Die Datenlage zur Beurteilung der onkologischen Sicherheit einer HRT nach gynäkologischen Malignomerkrankungen ist insgesamt unzureichend. Nach heutigem Kenntnisstand ist eine HRT nach Mamma- und Endometriumkarzinom grundsätzlich kontraindiziert. Nach Ovarialkarzinomerkrankung kann eine HRT nach Risiko-Nutzen-Abwägung durchgeführt werden, während nach Vulva-, Vaginal- oder Zervixkarzinom in der Regel keine Kontraindikation für eine HRT besteht. 


\section{Introduction}

The female menopause or climacteric denotes the transition from full ovarian function in the premenopausal period to a deficiency of oestrogen synthesis in the postmenopausal period. The onset and duration of menopause differ from woman to woman [1].

The hormonal change is a natural process that takes place at an average age of 51 years, but symptoms may occur, such as hot flushes, night sweats, dyspareunia, hair loss, forgetfulness, depression or sleep disorders [2]. The combination of symptoms is often termed the climacteric syndrome. Whether and how severely women suffer from menopausal symptoms varies individually. Many women experience such symptoms, which are sometimes associated with a considerable impairment of quality of life and make medical treatment appear reasonable [3].

Hormone replacement therapy (HRT) with oestrogens and progestogens is the most effective treatment for climacteric complaints. Vasomotor symptoms such as hot flushes and atrophy of the vaginal mucosa and vulva are indications for HRT [4]. Counselling should include adequate patient information regarding the different benefits and risks of HRT.

The initial misinterpretation of the WHI (Women's Health Initiative) study led to an irrational fear of HRT in both the population and the medical profession. For many physicians, the logical and safe conclusion appeared to be that HRT should be avoided, on the assumption that prescribing oestrogen alone or with progestogens entails oncological and thromboembolic risks.

Even before the WHI results, however, it was known that premature menopause and hypogonadism can reduce women's life expectancy by years due to their skeletal and cardiovascular effects and this negative effect correlates with the length of the hypo-oestrogenaemic period [5]. Rejection of HRT should also be supported by evidence and weighed against the potential benefits of HRT

Rapid advances in oncology have led to an increased survival rate in cancer patients, who live long enough either to reach the natural age of menopause or experience the end of gonadal function as a side effect of their oncological treatment (e.g., removal of the ovaries, radiation or treatment with anti-oestrogens). Ever more cancer survivors and physicians are faced with the question of hormone replacement therapy (HRT) after the completion of oncological therapy. The oncological risk of HRT in cancer survivors is extremely difficult to estimate, however.

Patients with breast, endometrial or ovarian cancer who develop menopausal symptoms are the major challenge as these diseases are hormone-dependent and HRT possibly increases the risk of recurrence. The data are insufficient to derive a standardised approach. Individual counselling is particularly important in this case.

\section{HRT After Breast Cancer}

The results of studies on the use of HRT in women who have had breast cancer are controversial. On the one hand, the HABITS trial (RCT) showed a marked increase in the risk of recurrence due to HRT but other studies, on the other hand, including the Stockholm study, did not find that use of HRT increased the risk of re- currence after treated breast cancer [6]. However, these studies have considerable weaknesses (e.g. small case numbers, short follow-up) so that a reliable conclusion cannot be drawn. According to the LIBERATE study, use of tibolone to treat climacteric complaints is also not safe. This study showed that the use of tibolone led to an increase in the risk of recurrence [7].

Vaginal oestrogen therapy after breast cancer represents a special case. A series of studies confirmed both efficacy for vaginal atrophy and an increase in the serum oestrogen level after topical use [8]. Nevertheless, treatment with ultra-low-dose oestrogen (e.g., oestriol $0.03 \mathrm{mg}, 3$ applications per week) appears to be justifiable for women after breast cancer who are suffering considerably.

In this connection, according to the guideline programme of the DGGG, OEGGG and SGGG, HRT can increase the risk of recurrence after treated breast cancer and should not be used in women who have had breast cancer. It can be considered in an individual case after non-hormonal treatments have failed and quality of life is substantially impaired ( $\bullet$ Table $\mathbf{1}$ ).

\section{HRT After DCIS}

Ductal carcinoma in situ (DCIS) is a non-invasive precursor lesion of breast cancer. The association between HRT and the risk of DCIS has been investigated in studies. The data are not consistent. Individual studies have not shown any association between DCIS and current use of HRT. However, a meta-analysis from 2012 regarding the risk of breast carcinoma in situ after HRT reports statistical significance (with oestrogen monotherapy/ET) or a nonsignificant relative risk/odds ratio of $\geq 1$ (oestrogen-progestogen therapy/EPT) [9].

In 2013 Luo et al. [10] used the data of the Women's Health Initiative to assess the effects of hormone therapy on the DCIS risk in two groups (users of conjugated equine oestrogens/CEE + medroxyprogesterone acetate/MPA or CEE only users versus nonusers). Compared with non-users, CEE + MPA was associated nonsignificantly with a higher DCIS risk over an average period of 11 years. Corresponding results of observational studies confirm an increased risk for DCIS in CEE + MPA users compared with women who were non-users ( $H R=1.65$; $95 \% \mathrm{Cl} 1.25-2.19)$. There was no clear association between treatment with CEE only and the risk of DCIS. Data from the CEE group showed that the DCIS risk in the treatment group was lower - however not significantly - in the placebo group. This analysis suggests that the combined use of oestrogen plus progestogen can increase the DCIS risk in women after menopause. Whether use of oestrogen alone is associated with DCIS requires further investigation.

There are hardly any data on the use of HRT after DCIS so no evidence-based recommendation can be deduced.

The various results referred to above contribute to a small literature that remains inconclusive. As long as the question remains unanswered as to how HRT correlates with the DCIS risk and whether DCIS is likewise a contraindication to HRT, HRT should not be suggested routinely after DCIS. Nevertheless, the benefit of HRT can be important for individual women [11] ( $\triangleright$ Table 1). 
- Table 1 Recommendations regarding HRT after gynecological malignancies.

\begin{tabular}{|c|c|c|c|}
\hline HRT after: & Histological classification & Recommendation & Comment \\
\hline \multirow[t]{2}{*}{ Breast cancer } & Invasive breast cancer & Fundamentally contraindicated & \multirow{2}{*}{$\begin{array}{l}\text { Non-hormonal alternatives preferable } \\
\text { HRT can be considered in case of substan- } \\
\text { tial impairment of quality of life }\end{array}$} \\
\hline & DCIS & No data & \\
\hline Endometrial cancer & & Primarily contraindicated & $\begin{array}{l}\text { Non-hormonal alternatives preferable } \\
\text { FIGO stage I: HRT can be considered } \\
\text { Combined HRT preferable }\end{array}$ \\
\hline \multirow[t]{2}{*}{ Uterine sarcoma } & $\begin{array}{l}\text { Carcinosarcoma, } \\
\text { adenosarcoma }\end{array}$ & Can be considered & - \\
\hline & $\begin{array}{l}\text { Leiomyosarcoma, endo- } \\
\text { metrial stromal sarcoma }\end{array}$ & Primarily contraindicated & - \\
\hline \multirow[t]{2}{*}{ Ovarian cancer } & Epithelial ovarian tumours & Risk-benefit assessment & $\begin{array}{l}\text { No risk-enhancing effect } \\
\text { Overall survival prolonged } \\
\text { RCTs required }\end{array}$ \\
\hline & Rare types & $\begin{array}{l}\text { Not recommended or not } \\
\text { enough data }\end{array}$ & - \\
\hline \multirow[t]{2}{*}{ PBSO with BRCA mutation } & With breast cancer & Contraindicated & \multirow{2}{*}{$\begin{array}{l}\text { Until the age of natural menopause } \\
\text { Oestrogen monotherapy preferable }\end{array}$} \\
\hline & No disease & Can be offered & \\
\hline \multirow[t]{2}{*}{ Cervical cancer } & Squamous epithelial cancer & \multirow[t]{2}{*}{ Not contraindicated } & - \\
\hline & Adenocarcinoma & & $\begin{array}{l}\text { Oestrogen-progestogen therapy } \\
\text { preferable }\end{array}$ \\
\hline \multirow[t]{2}{*}{ Vaginal cancer } & Squamous epithelial cancer & Not contraindicated & - \\
\hline & Adenocarcinoma & No data & $\begin{array}{l}\text { Most commonly after diethylstilboestrol } \\
\text { exposure in utero }\end{array}$ \\
\hline \multirow[t]{2}{*}{ Vulvar cancer } & Squamous epithelial cancer & Not contraindicated & - \\
\hline & Adenocarcinoma & No data & - \\
\hline
\end{tabular}

\section{HRT After Endometrial Cancer}

Studies such as the WHI study and the Million Women Study have shown that chronic oestrogen exposure of the endometrium increases the risk for endometrial hyperplasia and endometrial cancer, while the addition of progestogen ensures endometrial protection. However, there are insufficient data on HRT after endometrial cancer.

The available data (both individual RCTs and meta-analyses) do not indicate a significant risk of recurrence when HRT is used after treatment of early-stage endometrial cancer. There is no information on the use of HRT in endometrial cancer at a later stage (FIGO stage II and higher) [12].

A systematic review from 2020 [13] also showed that the use of HRT did not have a negative influence on the prognosis of survivors of stage I and II endometrial cancer. The influence of HRT in women with higher tumour stages remains unclear, however. The decision for or against the use of HRT after treatment of endometrial cancer should be individualised according to impairment of quality of life and taking into account that the evidence is limited. Especially in the early stages HRT at least does not appear to lead to a significant increase in risk. HRT was started after disease-free survival of 1 to 60 months (after operation) but in most cases the interval after the operation was between 3 and 12 months.
Based on a meta-analysis from 2014, when HRT is considered after endometrial cancer, combined HRT should be recommended. The meta-analysis showed that oestrogen and progestogen HRT had a protective effect against cancer recurrence, whereas oestrogen-only therapy did not have this effect [14].

Crandall et al. [15] analysed data from participants in the WHI study regarding the vaginal use of oestrogens and the risk of endometrial cancer among other things. In women with an intact uterus the risk for endometrial cancer did not differ significantly between women who used vaginal oestrogens and women who were non-users. In women who have already had endometrial cancer, an increased risk of recurrence due to vaginal oestrogen monotherapy cannot be excluded. When quality of life is considerably impaired due to urogenital complaints (vaginal dryness, dyspareunia, urge and stress incontinence), thus interfering with the woman's sexuality and quality of life, non-hormonal alternatives should be preferred initially according to the guidelines of the DGGG, OEGGG and SGGG. The data are too weak to allow generalised recommendations. Since oncological safety cannot be ensured, the use of topical oestrogens after treatment of endometrial cancer should be discussed with the patient and informed consent obtained.

In summary, according to the guideline programme of the DGGG, OEGGG and SGGG, both systemic HRT and topical oestro- 
gen monotherapy can be considered after unsatisfactory treatment with non-hormonal alternatives ( $\bullet$ Table 1$)$.

\section{HRT After Uterine Sarcoma}

Uterine sarcomas include leiomyosarcomas, carcinosarcomas, adenosarcomas and endometrial stromal sarcomas. It has been reported that endometrial stromal sarcomas over-express oestrogen and progesterone receptors and that oestrogen HRT and tamoxifen have a detrimental influence on the disease course. HRT should therefore be avoided with these tumours. Although leiomyosarcomas also over-express oestrogen and progesterone receptors very frequently, the data are controversial. Since removal of the ovaries did not improve 5-year survival, some authors suggest that leiomyosarcoma is not hormone-sensitive and that HRT can therefore be considered. Others regard HRT as too risky, however, while there are no direct data to confirm its safety. HRT can be used in carcinosarcoma and adenosarcoma [16] ( Table 1).

\section{HRT After Ovarian Cancer}

A natural or therapy-induced postmenopausal situation may be present in patients after treated ovarian cancer. The resulting climacteric symptoms can greatly interfere with quality of life. Young women, in particular, who are postmenopausal following treatment have a higher risk for diseases such as coronary heart disease or osteoporosis. There have not been many studies on the safety of HRT after ovarian cancer [17]. The majority of the studies refer to epithelial ovarian tumours, which account for about $90 \%$ of all malignant ovarian tumours. HRT does not appear to increase the risk of recurrence and even prolongs survival significantly $[16,18]$. There are not enough data on the use of HRT after rarer types of ovarian cancer. After germ cell tumours, HRT probably does not confer any additional risk of recurrence. Avoidance of HRT is recommended after endometrioid ovarian cancer [16].

A recent systematic review article from the Cochrane Database comes to the conclusion that HRT slightly improves the overall survival of women who have undergone surgical treatment because of epithelial ovarian cancer but the evidence certainty for this is low. The authors emphasise that the results can be interpreted with caution and that future well-designed RCTs are required to examine the oncological safety [19].

The aforementioned studies have a range of weaknesses (e.g., premature discontinuation, heterogeneous patient populations) so that the safety of HRT after ovarian cancer continues to remain unclear and no reliable conclusion can be drawn regarding oncological safety. Since all studies have shown, however, that there is not a risk-increasing effect but rather a risk reduction, according to the guideline programme of the DGGG, OEGGG and SGGG, HRT can be used when there is considerable impairment of quality of life and after appropriate information. Especially in young women after iatrogenic menopause, there is an increased mortality risk due to the occurrence of coronary heart disease so HRT appears reasonable in these patients ( $\triangleright$ Table $\mathbf{1}$ ).

\section{HRT After Prophylactic Bilateral Salpingo-Oophorectomy (PBSO)}

Women with an increased risk for breast and ovarian cancer because of a BRCA1 or BRCA2 mutation are a special group. Salpingo-oophorectomy to reduce the risk is recommended prior to menopause for women still without disease [20]. The role of hormone replacement therapy (HRT) in BRCA mutation carriers who undergo PBSO has been discussed controversially. In the general population, early menopause is associated with poorer quality of life and cognitive function and with an increased risk of bone and cardiovascular disease so that HRT is recommended up to the average age of menopause [21]. Controversial data have been published regarding HRT and breast cancer risk. For BRCA mutation carriers a possible increase in the already increased breast cancer risk is of great importance. Although the evidence is limited, HRT after PBSO has benefits and appears to have no influence on the breast cancer risk in BRCA mutation carriers after prophylactic mastectomy [22].

HRT can be offered to BRCA mutation carriers who undergo PBSO and do not have breast cancer up to the age of natural menopause, and also when prophylactic mastectomy has been performed. HRT is contraindicated in BRCA mutation carriers who already have breast cancer.

The non-increased breast cancer risk of HRT after PBSO in BRCA mutation carriers is also confirmed in the meta-analysis by Marchetti et al. [23]. Comparison of the different HRT regimens suggests that oestrogen alone is associated with the lowest BC risk. HRT is contraindicated in BRCA mutation carriers with breast cancer [16] ( Table 1).

\section{HRT After Cervical Cancer}

Squamous cell carcinoma accounts for $80-90 \%$ of cases of cervical cancer and it is known that squamous cell cancers are not oestrogen-dependent. Ploch et al. showed, decades ago [24], that HRT was beneficial for patients either in oestrogen-only or in a combined oestrogen-progestogen form. The recurrence rate was $20 \%$ in the HRT group and the 5 -year overall survival was $80 \%$, while the rates were 32 and $65 \%$ respectively in the control group.

$10-20 \%$ of cases of cervical cancer are cervical adenocarcinomas, which show a marked increase in risk with oestrogen monotherapy $(\mathrm{OR}=2.7 ; 95 \% \mathrm{Cl}: 1.1-6.8)$. The risk is no longer found, however, when combined HRT is used in adenocarcinoma (RR 1.1; 95\% Cl: 0.26-5.0) [25]. In this case, the biological behaviour is similar to that of endometrial cancer. Accordingly, combined therapy with oestrogen-progestogen regimens should be preferred. According to our current knowledge, treated cervical cancer is not a contraindication to HRT [26]. Nevertheless, one study in Germany showed that fewer than half of all women diagnosed with iatrogenic menopause after cervical cancer received counselling and/or a prescription for HRT. These results reflect the need for clearer guidelines on HRT [27] ( $\bullet$ Table 1). 


\section{HRT After Vaginal and Vulvar Cancer}

Most vaginal and vulvar cancers are squamous epithelial cancers and thus not hormone-dependent [28]. HRT is therefore not contraindicated.

Vaginal (clear-cell) adenocarcinoma develops most frequently after diethylstilboestrol exposure in utero [29], and vulvar adenocarcinoma can develop from Bartholin's glands. These forms are too rare and there is a lack of data on their relationship to HRT. However, a few sporadic reports are found in the literature that suggest an association between oestrogen exposure and vaginal adenocarcinoma [30]. Because of the lack of data, no clear recommendation can be given ( $\triangleright$ Table $\mathbf{1}$ ).

\section{Conclusion}

Patients who have developed gynaecological malignancies (e.g., breast, endometrial or ovarian cancer) and suffer from the symptoms or consequences of natural or treatment-induced ovarian dysfunction during adjuvant therapy or after the completion of the primary treatment consider HRT. Since these diseases are hormone-dependent, HRT possibly increases the risk of recurrence.

The data needed to assess the oncological safety of HRT after the malignancies described above are insufficient overall. The majority of the meta-analyses do not show an increase in the risk of recurrence. Based on the number of included patients and other methodological weaknesses, however, the studies do not suffice to establish the safety of HRT after oncological therapy has concluded. There are also randomised studies for three of these malignancies, which found an increased risk of recurrence with HRT use after breast cancer, no increase in risk for endometrial cancer and in fact an improvement in survival for ovarian cancer. All studies have a range of methodological weaknesses, however, so that the safety of HRT after the aforementioned malignancies is unclear. HRT is therefore contraindicated after breast, endometrial or ovarian cancer. When quality of life is markedly impaired by climacteric symptoms and non-hormonal alternatives have failed, it can be considered in an individual case after appropriate informed consent. After vulvar, vaginal or cervical cancer there is usually no contraindication to HRT. In the case of ovarian cancer, uterine sarcoma, cervical cancer and vaginal/vulvar cancer, the histological classification should also be noted.

In summary, HRT can be considered if indicated, even after gynaecological malignancies. Non-hormonal alternatives should usually be preferred. A detailed history (examination of the indication, type of malignancy, histological classification, tumour stage, biological features, e.g., ER/PR status in breast cancer) is necessary and the decision for or against HRT should always be individualised and discussed with the patient, obtaining informed consent.

Initial data indicate that complementary and alternative medicine (CAM) can have a clinically significant effect in reducing hot flushes. Healthcare providers should consider the evidence regarding CAM in order to provide an integrative approach for symptom management in the menopause period [31].

\section{Conflict of Interest}

The authors declare that they have no conflict of interest.

\section{References}

[1] Avis NE, Crawford SL, Greendale G et al.; Study of Women's Health Across the Nation. Duration of menopausal vasomotor symptoms over the menopause transition. JAMA Intern Med 2015; 175: 531-539

[2] Gracia CR, Freeman EW. Onset of the Menopause Transition: The Earliest Signs and Symptoms. Obstet Gynecol Clin North Am 2018; 45: 585-597. doi:10.1016/j.ogc.2018.07.002

[3] Bacon JL. The Menopausal Transition. Obstet Gynecol Clin North Am 2017; 44: 285-296. doi:10.1016/j.ogc.2017.02.008

[4] Roberts H, Hickey M. Managing the menopause: An update. Maturitas 2016; 86: 53-58. doi:10.1016/j.maturitas.2016.01.007

[5] Langer RD. The evidence base for HRT: what can we believe? Climacteric 2017; 20: 91-96. doi:10.1080/13697137.2017.1280251

[6] Antoine C, Liebens F, Carly B et al. Safety of hormone therapy after breast cancer: a qualitative systematic review. Hum Reprod 2007; 22: 616-622

[7] Untch M, Beckmann MW, Emons G et al. The LIBERATE Study: Hormone Replacement Therapy with Tibolone Increases the Risk of Recurrence and Metastases in Breast Cancer Patients. Geburtshilfe Frauenheilkd 2009; 69: 199-201

[8] Donders G, Neven P, Moegele M et al. Ultra-low-dose estriol and Lactobacillus acidophilus vaginal tablets (Gynoflor((R))) for vaginal atrophy in postmenopausal breast cancer patients on aromatase inhibitors: pharmacokinetic, safety, and efficacy phase I clinical study. Breast Cancer Res Treat 2014; 145: 371-379

[9] Calvocoressi L, Stowe MH, Carter D et al. Postmenopausal hormone therapy and ductal carcinoma in situ: a population-based case-control study. Cancer Epidemiol 2012; 36: 161-168

[10] Luo J, Cochrane BB, Wactawski-Wende J et al. Effects of menopausal hormone therapy on ductal carcinoma in situ of the breast. Breast Cancer Res Treat 2013; 137: 915-925

[11] Sourouni M. Hormonersatztherapie und duktales Carcinoma in situ. J Gynäkol Endokrinol CH 2019; 22: 100-104

[12] Edey KA, Rundle S, Hickey M. Hormone replacement therapy for women previously treated for endometrial cancer. Cochrane Database Syst Rev 2018; (5): CD008830

[13] Di Donato V, Palaia I, D’Aniello D et al. Does Hormone Replacement Therapy Impact the Prognosis in Endometrial Cancer Survivors? A Systematic Review. Oncology 2020; 98: 195-201

[14] Shim SH, Lee S], Kim SN. Effects of hormone replacement therapy on the rate of recurrence in endometrial cancer survivors: a meta-analysis. Eur J Cancer 2014; 50: 1628-1637

[15] Crandall C], Hovey KM, Andrews CA et al. Breast cancer, endometrial cancer, and cardiovascular events in participants who used vaginal estrogen in the Women's Health Initiative Observational Study. Menopause 2018; 25: 11-20

[16] Deli T, Orosz M, Jakab A. Hormone Replacement Therapy in Cancer Survivors-Review of the Literature. Pathol Oncol Res 2020; 26: 63-78. doi:10.1007/s12253-018-00569-x

[17] Li D, Ding CY, Qiu LH. Postoperative hormone replacement therapy for epithelial ovarian cancer patients: a systematic review and meta-analysis. Gynecol Oncol 2015; 139: 355-362

[18] Eeles RA, Morden JP, Gore M et al. Adjuvant Hormone Therapy May Improve Survival in Epithelial Ovarian Cancer: Results of the AHT Randomized Trial. J Clin Oncol 2015; 33: 4138-4144. doi:10.1200/JCO.2015.60. 9719 
[19] Saeaib N, Peeyananjarassri K, Liabsuetrakul T et al. Hormone replacement therapy after surgery for epithelial ovarian cancer. Cochrane Database Syst Rev 2020; (1): CD012559

[20] Mau C, Untch M. Prophylactic Surgery: For Whom, When and How? Breast Care (Basel) 2017; 12: 379-384

[21] Sullivan SD, Sarrel PM, Nelson LM. Hormone replacement therapy in young women with primary ovarian insufficiency and early menopause. Fertil Steril 2016; 106: 1588-1599

[22] Gordhandas S, Norquist BM, Pennington KP et al. Hormone replacement therapy after risk reducing salpingo-oophorectomy in patients with BRCA1 or BRCA2 mutations; a systematic review of risks and benefits. Gynecol Oncol 2019; 153: 192-200

[23] Marchetti C, De Felice F, Boccia S et al. Hormone replacement therapy after prophylactic risk-reducing salpingo-oophorectomy and breast cancer risk in BRCA1 and BRCA2 mutation carriers: A Meta-analysis. Crit Rev Oncol Hematol 2018; 132: 111-115

[24] Ploch E. Hormonal replacement therapy in patients after cervical cancer treatment. Gynecol Oncol 1987; 26: 169-177
[25] Angioli R, Luvero D, Armento G et al. Hormone replacement therapy in cancer survivors: Utopia? Crit Rev Oncol Hematol 2018; 124: 51-60

[26] Vargiu V, Amar ID, Rosati A et al. Hormone replacement therapy and cervical cancer: a systematic review of the literature. Climacteric 2021; 24: 120-127. doi:10.1080/13697137.2020.1826426

[27] Rauh LA, Pannone AF, Cantrell LA. Hormone replacement therapy after treatment for cervical cancer: Are we adhering to standard of care? Gynecol Oncol 2017; 147: 597-600

[28] Sherman KJ, Daling JR, McKnight B et al. Hormonal factors in vulvar cancer. A case-control study. J Reprod Med 1994; 39: 857-861

[29] Herbst AL, Ulfelder H, Poskanzer DC. Adenocarcinoma of the vagina: association of maternal stilbestrol therapy with tumor appearance in young women. N Engl J Med1971; 284: 878-881

[30] Somoye GO, Gull S. Adenocarcinoma of the vaginal vault following prolonged unopposed oestrogen hormone replacement therapy. J Obstet Gynaecol 2005; 25: 220-221. doi:10.1080/01443610500050991

[31] Johnson A, Roberts L, Elkins G. Complementary and Alternative Medicine for Menopause. J Evid Based Integr Med 2019; 24: 2515690X19829380 